\title{
Mill Processing in Three Different Devices; The Effect of Intrinsic Intensity on the Material
}

G. Tarango-Rivero ${ }^{1}$, J.M. Mendoza-Duarte ${ }^{1}$, Francisco Robles-Hernandez ${ }^{2}$, C.D. Gómez-Esparza ${ }^{3}$, Caleb Carreño-Gallardo ${ }^{1}$, C.G. Garay-Reyes ${ }^{1}$, Ivanovich Estrada ${ }^{1}$ and R. Martínez-Sánchez ${ }^{1}$

${ }^{1}$ Centro de Investigación en Materiales Avanzados (CIMAV), Chihuahua, Chihuahua, Mexico, ${ }^{2}$ University of Houston, Houston, Texas, United States, ${ }^{3}$ Universidad Tecnológica de Tula-Tepeji, Tula de Allende, Hidalgo, Mexico

* Corresponding author: ivanovich.estrada@ cimav.edu.mx

Materials milling has been a process of fundamental interest in the industry for centuries, the typical objectives were mixing and particle size reduction looking for improving the intimate interaction between components. At present, high-energy ball milling (HEBM) involves repeated impacts of the sample with the grinding media which cause severe plastic deformation and fracture of particles trapped between the collision points reaching a fine and refined microstructure. HEBM can also produce unstable and amorphous materials from crystalline structures reducing the crystal structure of weak bonds. In the particular case of graphite (Gr) its layered structure with a relatively large separation among layers has a smaller binding energy between interlayered atoms. Thus, it is possible to induce $\mathrm{Gr}$ amorphization through the degradation of the layered structure by HEBM [1].

In this study, the effect of HEBM on the Gr microstructure using three different mills was evaluated. Selected devices were: Spex 8000M, Planetary (Pulverisette-7 Fritsch), and an EMAX (Retsch). Samples preparation was carried out using an argon atmosphere and $8 \mathrm{~h}$ of processing. In the Spex device, a vial is agitated at high frequency in complex 3D cycles, the average impact velocity is about $4.2 \mathrm{~ms}^{-1}$, the angular velocity is $\sim 80$ rounds s $^{-1}$, and the impact frequency reaches a value of $142 \mathrm{~Hz}$ [2]. In the planetary mill, the intensity depends on impact energy, the number of reached impacts, and abrasion; at 700 r.p.m., the calculated impact energy is $145 \mathrm{~J} / \mathrm{s}$ [3]. Emax mill is very recent, and related literature is scarce, in this device, both mechanisms: impact and friction are combined at a speed of 2,000 rpm. Fig. 1a shows some $\mathrm{X}$-ray diffraction patterns of the milled samples. The main peak (located at $26^{\circ}$ ) is generally related to the hexagonal Gr structure; it decreased in intensity getting wider after milling. This broadening effect is due to the lattice distortion that occurs in the $\mathrm{AB}$ stacking order of the graphite lattice showing substantial degradation as a result of HEBM. A rough estimation of crystallite size indicated sizes of 52, 48, and 42 $\mathrm{nm}$ for Spex, Planetary, and Emax mills, respectively. Fig. 1b shows the Gr (002) reflections of milled samples compared to a green line located at $26.5^{\circ}$, which corresponds to a lattice spacing of $0.335 \mathrm{~nm}$ from crystalline and ordered Gr structure. It is noticeable a shift to lower angles, meaning an increase of this spacing being more evident in the Emax device. Micrographs in Fig. 2 show the morphology and general characteristics of milled products; it notices an essential modification of the original $\mathrm{Gr}$ microstructure through ball milling. Experimental results showed that HEBM is a practical route for $\mathrm{Gr}$ disordering, and it is heavily related to the type of milling device and its intrinsic milling intensity. 

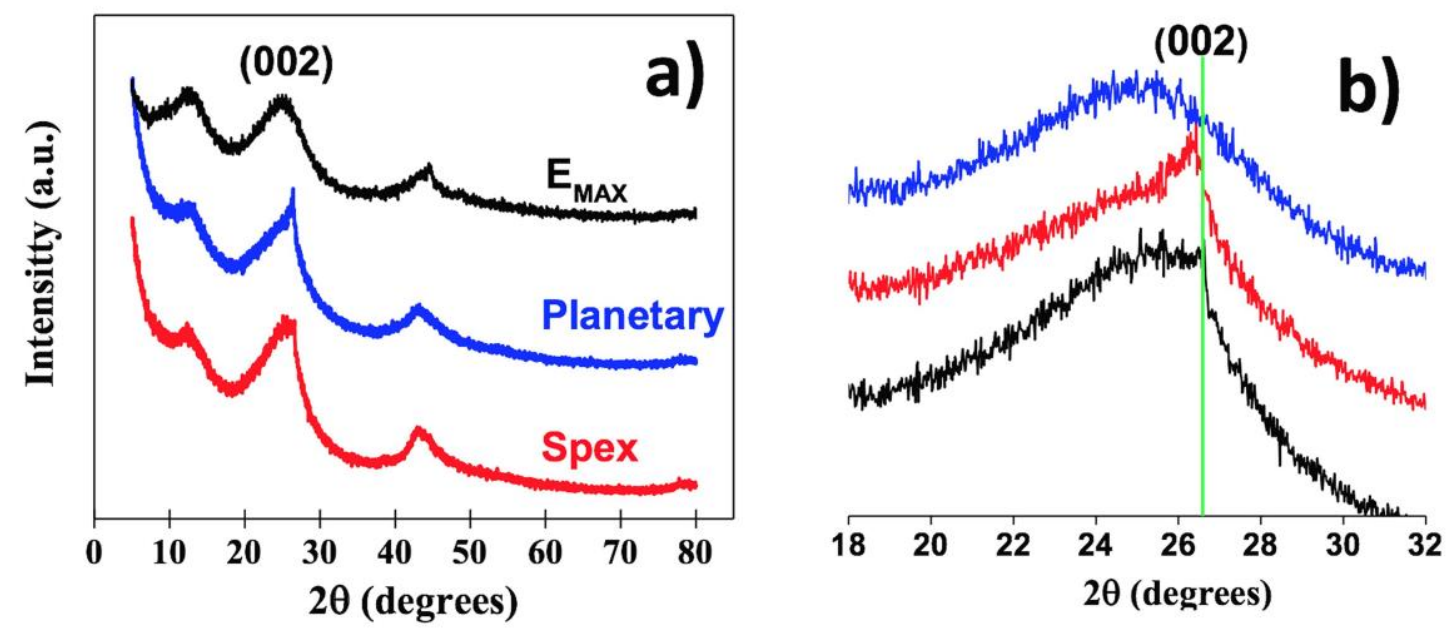

Figure 1. a) XRD patterns of milled samples and b) a close up of main diffraction Gr plane.
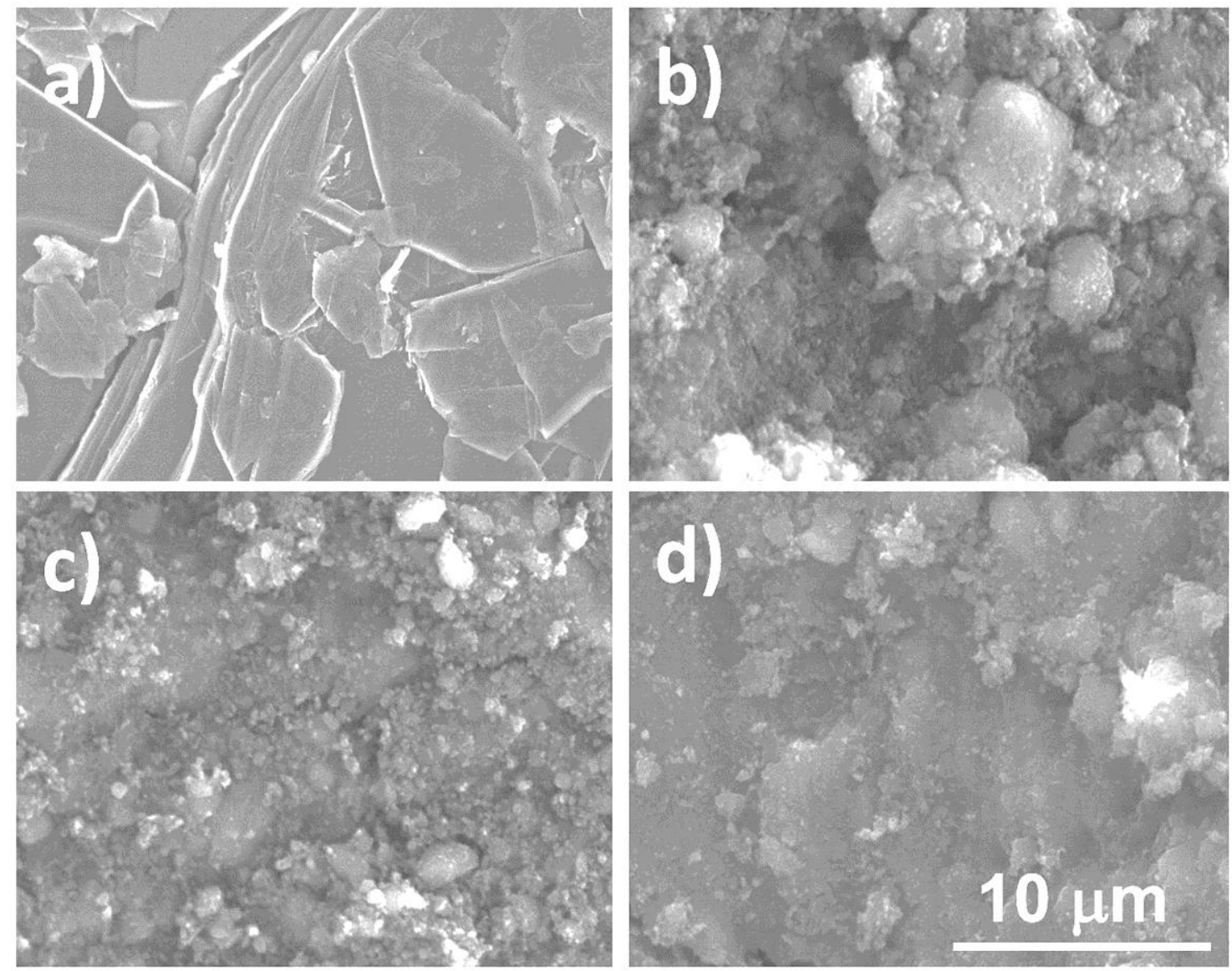

Figure 2. SEM micrographs of a) original Gr, b) Spex, c) Planetary, and d) Emax milled samples (5000X).

\section{References}

[1] T. Fukunaga, K. Nagano, et al., J. Non-Crys. Sol. 232-234 (1998), p. 416.

[2] A. Concas, N. Lai, M. Pisu, G. Cao, Chem. Eng. Sci. 61 (2006), p. 3746.

[3] H. Ashrafizadeh, M. Ashrafizaadeh, Adv. Pow. Tech. 23-6 (2012), p. 708. 